\title{
Apnoeic episodes induced by smothering: two cases identified by covert video surveillance
}

\author{
D P SOUTHALL, V A STEBBENS, S V REES, M H LANG, J O WARNER, \\ E A SHINEBOURNE
}

\begin{abstract}
Recurrent cyanotic episodes associated on some occasions with loss of consciousness due to cerebral hypoxia were investigated by long term tape recordings of breathing activity, oxygen saturation, air flow, electrocardiographic activity, and in some cases electroencephalographic activity. In 51 infants and children the mechanisms for the cyanotic episodes were identified (prolonged expiratory apnoea in 45 , sleep related airway obstruction in three, seizure induced apnoea in one, behaviour induced apnoea in one). In one child apnoea was suspected as being caused by suffocation (smothering) by the mother. This was confirmed after enlisting the help of the police, who undertook covert video surveillance during cyanotic episodes. Each cyanotic episode was associated with a pattern of disturbance on the multichannel tape recordings which may be pathognomonic of this type of apnoea.

A second infant with cyanotic episodes in whom smothering was suspected was referred for similar investigation after the availability of video recordings became established. Maternal smothering was again supported by specific patterns on multichannel tape recordings and confirmed by video surveillance.

Diagnosis by video surveillance produces unequivocal evidence in these cases and avoids the need for medical and nursing staff to confront the mother with a possibly incorrect suspicion or in a court of law.
\end{abstract}

\footnotetext{
Department of Paediatrics, Cardiothoracic Institute, Brompton Hospital, London SW3 6HP

D P SOUTHALL, MD, MRCP, senior lecturer and honorary consultant in paediatrics

V A STEBBENS, BSC, research assistant

$S$ V REES, BA, CQSW, paediatric social worker

$M$ H LANG, research assistant

J O WARNER, FRCP, DCH, consultant paediatrician

E A SHINEBOURNE, MD, FRCP, consultant paediatric cardiologist

Correspondence and requests for reprints to: Dr Southall.
}

\section{Introduction}

Child abuse is a recognised cause of cyanotic episodes in infants and young children.$^{1-7}$ In some instances this kind of abuse has led to death ${ }^{7}$ or irreversible central nervous system damage. ${ }^{16} \mathrm{We}$ describe two cases in which covert video surveillance was used to confirm asphyxiation by mothers as the cause of cyanotic episodes. Analysis of multichannel tape recordings of physiological variables during episodes of asphyxia showed a characteristic pattern which may be of value in alerting investigators to this cause of apnoea.

\section{Case 1}

A boy infant was the third born to a 22 year old mother and 51 year old father. After an uneventful pregnancy, caesarean section, and early postnatal history the infant suffered a cyanotic episode at 4 months of age. Repeated episodes occurred at least once a week until their cause was determined at 22 months of age. Inumerable investigations at a district general hospital and at hospitals specialising in paediatric neurology and cardiology had failed to disclose the cause. The child had been treated, without benefit, with anticonvulsants and with atropine for suspected reflex anoxic seizures. The parents had used a monitor (Graseby Dynamics MR10) set to trigger alarms after $\mathbf{2 0}$ seconds of absent abdominal movements. The oldest child in the family (aged 5) was reported to have suffered cyanotic episodes attributed to "breath holding" during infancy and early childhood.

At 20 months of age the child was admitted to the Brompton Hospital. The mother was unable to give a clear description of the onset of his cyanotic episodes. She claimed that episodes most frequently began during sleep, that she had never been present when they started, and that she had usually found him cyanosed after being alerted by the apnoea alarm. A history was taken concentrating on the symptoms of three conditions known to produce episodes of cyanosis. The first, prolonged expiratory apnoea ${ }^{8}$ (cyanotic breathing holding), was considered to be unlikely because episodes never occurred after an attempt to cry, nor was there any cyanosis during crying. The second, sleep related upper airway obstruction (D P Southall et al, unpublished observations), was considered extremely unlikely, as there was no history of inspiratory stridor, chest recession, frequent awakenings, daytime drowsiness, or the other reported features of this condition. The third, seizure induced apnoea, ${ }^{9}$ was suspected as such episodes often occur during sleep and the mother reported the monitor alarms being triggered during this time. On further questioning the mother stated that she had noticed convulsive movements during some of the episodes.

On examination the child was pale but showed no other abnormalities. 
Motor performance and sensory perception were appropriate for age but his vocabulary consisted of only two words. His social behaviour, including his relationship with his mother, appeared normal. He was admitted to the paediatric intensive care unit for a series of multichannel tape recordings of physiological variables. The first consisted of beat to beat arterial oxygen saturation (from a modified Nellcor pulse oximeter), arterial pulse waveform (from the same instrument), abdominal breathing movements (from a pressure capsule (Graseby) and pressure transducer within the oximeter), and expired carbon dioxide from a scavenger tube on the upper lip sampling from one nostril (Engstrom Eliza). No cyanotic episodes occurred during this recording and all measurements and breathing patterns were normal, as defined by investigations on age matched healthy controls.

The next night, by using a four channel tape recorder plus a four channel multiplexer, two channels of the electroencephalogram (centrotemporal) were added. To provoke seizures the child was deprived of sleep, being awoken at 0700 and kept awake until 1900 . At 2225 his mother called the nursing staff, who found the child cyanosed and unconscious. They gave oxygen by bag and facemask. He recovered consciousness and colour after five minutes but remained disorientated and subsequently slept for several hours. His mother reported that she heard a "rattling noise" coming from his cot, went to him, and found him "blue" and unconscious.

Analysis of the tape recording showed that this cyanotic episode began during relatively regular breathing suggesting sleep. There was the sudden onset of large amplitude signals from the abdominal pressure capsule, suggesting body movements. Pronounced tachycardia and electromyographic artefact were noted on both electroencephalogram channels. The pulse waveforms and therefore oxygen saturation signals were uninterpretable because of movement artefact. After 70 seconds large amplitude $\theta$ and $\delta$ waves appeared on both electroencephalogram channels with a subsequent isoelectric baseline signal. The gross movements stopped at this time, to be followed immediately by pauses in abdominal movements (for up to 19 seconds) and large amplitude, slow breathing with a prolonged expiratory phase (gasping).$^{10}$ There was no evidence of seizure activity preceding the episode. The features suggested acute upper airway obstruction associated with progressive hypoxaemia and subsequent cerebral hypoxia. Mother and child returned home while expert opinions were sought on the electroencephalogram signals.

Four weeks later the child was readmitted. Shortly after admission he suffered a severe cyanotic episode while alone in the bathroom with his mother. The nursing staff were summoned and found him unconscious and severely cyanosed. After emergency cardiorespiratory resuscitation he recovered consciousness and oxygenation but remained pale, sweaty, and tachycardic for several hours.

Two further episodes occurred during tape recordings during sleep and with the mother present at onset. The nursing staff were called after the events had become established and resuscitative measures instituted. Analysis of the tape recordings showed the onset, during relatively regular breathing, of large body movements continuing for 46 and 69 seconds respectively. In the second episode similar electroencephalographic changes to those described above and "gasping" respiratory movements occurred after 72 seconds. On both occasions there was loss of interpretable oxygen saturation signals. In the second episode the pulse oximeter probe disconnected five seconds after the onset of the attack and reconnected shortly after the end of the large body movements. Disconnection of the pulse oximeter probe produces a different artefact from that of movement artefact. In the former the amplitude of the pulse waveform signal becomes zero; in the latter there is a continuously varying signal as the microprocessor searches for pulse waveforms.

It was after the analysis of these recordings that the possibility of suffocation (smothering) by the mother was first considered. Analysis of all hospital records disclosed that no episodes had occurred in the absence of the mother and that none had begun in the presence of a third person. Information from the father was equivocal.

When the child was 13 months old the referring paediatrician had informed the mother that further investigations were unnecessary. The child appeared to be thriving and the paediatrician suggested that further investigations would be instituted only if there was evidence of severe cerebral hypoxia, as manifested by convulsions or loss of consciousness. $\mathrm{He}$ explained that these signs might indicate temporary or permanent neurological damage. Roughly one week later the child was admitted to a neighbouring hospital unconscious and hypoxaemic after a prolonged cyanotic episode. Recovery of consciousness was protracted and there was concern that there might be permanent neurological damage. Thereafter most of his episodes included loss of consciousness and convulsions.

Nursing and medical staff were alerted to the possibility of smothering and asked to increase supervision, partly for the child's safety and partly to observe the onset of a cyanotic episode. The child was placed in a cubicle where he shared a nurse only with the patient in the adjacent cubicle. A multichannel recording was started after sleep deprivation. At 2140 the nurse was with the mother and sleeping child. The mother said that she was going to the toilet and started to leave the cubicle. Simultaneously the patient in the next cubicle called the nurse away. Two minutes later the nurse returned. She assumed that the mother was in the toilet but found her in the cubicle doorway calling out that a cyanotic episode was occurring. The nurse went in and resuscitated the child. The signals recorded during this cyanotic episode did not include an electroencephalogram but showed large body movements for 72 seconds and absent airflow for 94 seconds (fig 1), features suggestive of acute airway obstruction. Gasping respiratory movements were also identified (fig 1). Examination of the airway under general anaesthesia using a $2.9 \mathrm{~mm}$ fibreoptic laryngoscope and a rigid bronchoscope found no evidence of structural lesion that might intermittently be occluding the airway.

\section{INDICATIONS FOR VIDEO SURVEILLANCE}

An informal multidisciplinary conference was held among members of the administrative, medical, nursing, and social service staff and possible ways of excluding or substantiating the "smothering" hypothesis discussed. The suggestion that the mother should leave the child at the hospital with another member of the family, allowing the frequency of episodes to be monitored, was raised. This, however, had already been refused by the mother when it had been suggested in another context. Direct confrontation was discussed but dismissed. Denial was considered to be the likely response and if the hypothesis proved correct this approach might place the child in more danger. If the hypothesis was incorrect confrontation might place intolerable pressures on the mother and family with unknown consequences. It was also considered that all the evidence was circumstantial and insufficient in its own right to enable a care order to be granted. It was agreed, therefore, that to validate or reject the smothering hypothesis covert videotape surveillance was the only practical solution. 


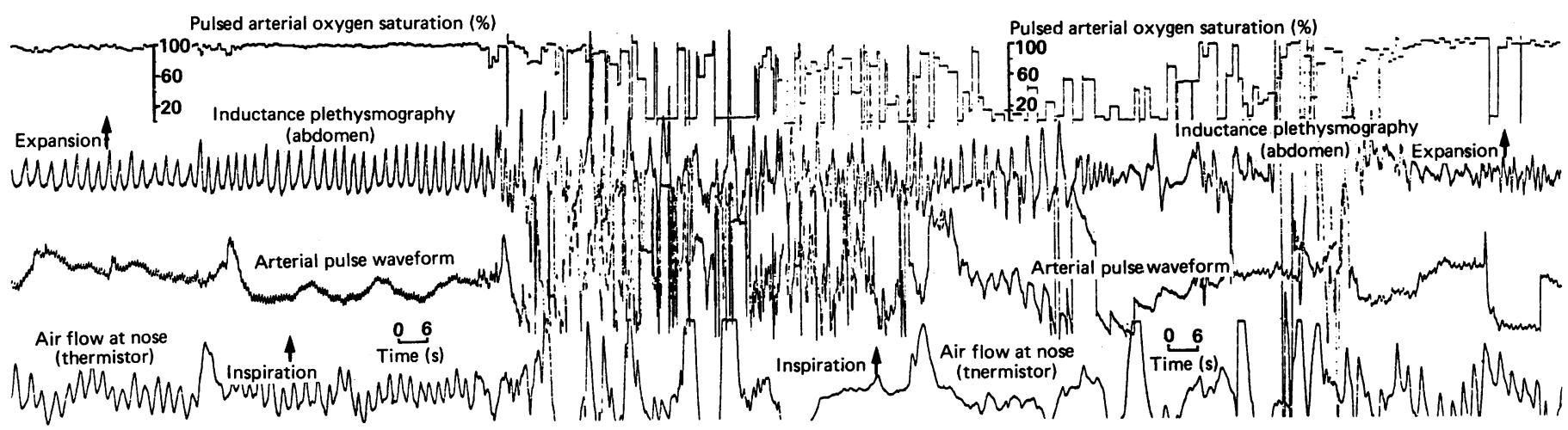

It was also agreed that it might be dangerous for the mother to take the child out of the hospital before a definite answer had been established, particularly given the increasing frequency and severity of the episodes. The social services were alerted and it was agreed that a place of safety order, if necessary through the police, would be obtained as an emergency if the mother insisted on leaving. The police were contacted and that evening established video surveillance in a cubicle in the paediatric intensive care unit. The camera was connected to a visual display unit and tape recorder in an adjacent room with women police constables providing continuous surveillance. The multichannel physiological recording equipment was also attached to the child, thus anchoring him within the field of vision of the camera and linking in time observed and recorded events during any subsequent cyanotic episode.

Sixteen hours after the onset of video monitoring the child was asleep in the cubicle with only his mother in attendance. She moved her chair away from the cot and lowered the cot sides. She then placed a soft garment (a tee shirt) on to the bedding close to the child's face. Five minutes later she placed the garment over his nose and mouth and forced his head on to the mattress. He awoke immediately and struggled violently. After 10 seconds the policewomen alerted the nurses, who went into the cubicle. The mother claimed that she was checking his arm, which she said had been twitching. The child was settled back to sleep. It had been agreed with the police that intervention was to be delayed for 40 seconds, a time known from previous recordings to be short of that associated with asphyxial electroencephalographic changes. Such a length of smothering should also produce a tape recorded signal comparable with those taken previously. In the first episode the woman police officer had intervened prematurely because of distress at what she had seen. She decided to continue surveillance. Twenty minutes later when the child was asleep on his side and mother was again alone in the cubicle she placed him in a supine position with his face upright and tucked his arms under the bedding. Ten minutes later she again applied the garment over his nose and mouth and forced his head on to the mattress. The child struggled violently. Forty two seconds later the nursing staff were alerted by the police and went into the cubicle. They found him conscious without cyanosis. The mother claimed that he had woken screaming and that she was comforting him.

Shortly afterwards the mother was interviewed by medical and nursing staff and a psychiatric social worker. She was informed of the video recording and admitted to smothering her child. She stated, however, that only the last two, recorded events were induced by smothering. She later retracted this and admitted that she had induced all but the first few cyanotic episodes in early infancy, which, she claimed, had occurred spontaneously. She also stated that her behaviour was an attempt to draw attention to intolerable pressures at home and that she did not intend to do her child any harm. She stated that her eldest daughter's cyanotic episodes were not due to smothering. She was admitted into police custody and the child taken into care.

Examination of the tape recording of physiological variables during the videotape recording showed that the events were similar to those recorded previously, being characterised by large body movements with resultant disruption of oxygen signals and 42 seconds of absent air flow.

Further investigations disclosed that the eldest daughter in the family had suffered a head injury at 7 months as a result of a fall in her mother's arms. On admission to the casualty department the mother had claimed that the child had been unconscious for two to three minutes. There was no skull fracture or any other fracture on a skeletal survey. Two days later the child was readmitted to the casualty department having banged her head in the cot, thus enlarging the haematoma. At 2 years 7 months this same child was admitted to hospital having ingested some of her mother's tranquillisers. She had not been placed on the "at risk" register. The second child in the family was referred to the paediatrician at 7 months of age with paucity of movements in his right hand. This did not persist and he was discharged without further investigation or treatment.

The mother claimed that as a teenager she had suffered frequent and severe physical abuse from her father. She was sentenced to three years' probation with a recommendation that she should have psychiatric treatment.

\section{Case 2}

This infant was the second born to a 22 year old mother and 21 year old father. She weighed $3120 \mathrm{~g}$ at birth and was delivered vaginally at term. At 2 years of age her elder sister had suffered a burn to her left arm and chest from hot coffee.

The child suffered a first cyanotic episode at 3 weeks of age and a total of seven attacks had been reported by the time of the diagnosis at 6 months. No cause for these episodes had been found in the local hospital despite extensive investigations, including electroencephalography. The parents had been issued with an abdominal movement apnoea monitor (Graseby MR10).

The second cyanotic episode at 5 months of age was particularly severe. The episode occurred at home and the baby was thought by the ambulancemen to be unconscious and was given oxygen during the transfer to hospital. On arrival in the casualty department she was pale and sweating and had shallow breathing and sinus tachycardia. The mother was distressed to the point of being hysterical. Later in this admission the infant was found deeply cyanosed on the childrens' ward. The mother claimed that the infant had been asleep and that the monitor had been triggered. She had found her baby having a cyanotic episode and alerted the nurses. Her subsequent description of this episode, particularly with regard to the apnoea monitor alarm, contained inconsistencies. When seen by a consultant paediatrician 30 minutes after the episode the infant was pale, floppy, sweaty, and had a tachycardia.

For the following reasons the paediatrican suspected smothering by the mother. The onset of all episodes occurred in the presence of the mother alone, her description of the sequencing of clinical signs was inconsistent, and the health visitor had found that the apnoea monitor was not being used at home. Because of the cyanotic episodes the mother was seeking installation of a telephone and better housing. During two prolonged discussions with the mother the paediatrician had attempted without success to draw out any problems that she might be having within her family. Direct confrontation was considered but rejected because of the likelihood of denial. The paediatrican became aware of the video surveillance used in case 1 and referred the child to the Brompton Hospital.

On admission the infant was thriving but noticeably irritable. Successive tape recordings of physiological variables (as in case 1) were undertaken. During the first overnight recording a pattern characteristic of the episodes in case 1 and lasting 71 seconds was identified. The mother stated that she had reported this to the nursing staff, but no evidence of this could be found in the nursing notes or on questioning the nursing staff. A further overnight recording of the same signals was undertaken in the paediatric intensive care unit. At 2230 the mother, who was sleeping in a bed next to her infant's cot, summoned the nurse into the cubicle. The infant was cyanosed and unconscious and was given oxygen by bag and facemask. Analysis of the tape recording showed the sudden onset during regular breathing of large body movement signals lasting 84 seconds; 12 seconds later there were slow abdominal movements with a prolonged expiratory phase (gasping respiratory movements) lasting 26 seconds (fig 2 ). The mother claimed that the infant had been asleep and that she happened to notice the cyanosis when she glanced into the cot. 
The police were contacted and video surveillance similar to that in case established along with a tape recording of physiological signals. About four hours after the start of surveillence, when the mother was alone in the cubicle with her infant, she was seen to switch off the apnoea monitor and place a soft garment under the front of her own tee shirt. Ten minutes later she placed this garment over the face of her sleeping infant, forcing her head into the mattress. The infant awoke and began to struggle. Fifteen seconds after the onset of suffocation the police sent a nurse into the cubicle. She found the infant to be awake and well. There was no cyanosis. When the nurse was not looking the mother switched the apnoea monitor back on and placed the garment she had used under her own shirt. The mother was then arrested. On later questioning she admitted to inducing all episodes of cyanosis. She stated that as a teenager she had suffered physical abuse from her father, on one occasion being admitted to the local casualty department with severe facial injuries. She had also felt unwanted as a child and been very unhappy. She was married and stated that her husband did not know about the smothering. In court the mother was given two years' probation with the directive that she should receive psychiatric treatment.

\section{Results of investigations on 50 other children presenting with repeated cyanotic episodes}

Between October 1984 and June 1986 a total of 51 infants presented with repeated but unexplained episodes of cyanosis. By means of a similar protocol of investigations but not including video recordings 50 were explained, the remaining case being our case 1 . Abnormal episodes of apnoea (transient absence of ventilation of whole or part of the alveolar bed) were documented in these 50 cases. Most ( 45 cases) were explained by prolonged expiratory apnoea.$^{8}$ One was due to seizure induced apnoea, ${ }^{9}$ one infant had a neurological disorder akin to Rett's syndrome with behaviour induced prolonged apnoeic pauses when awake, ${ }^{11}$ and three had sleep associated upper airway obstructive apnoea (Southall et al, unpublished).

\section{Discussion}

Smothering was identified as the cause of frequent and severe cyanotic episodes in one of 51 children. One additional case was identified after our use of video surveillance had been recognised. Many features of these case histories have been described in the syndrome termed Munchausen by proxy. Thus the onset of cyanotic episodes occurred only in the presence of the mothers and there were inconsistencies in their descriptions of the sequencing of the clinical signs. Both mothers were intelligent and exhibited helpful and unusually calm behaviour in the hospital, befriending many of the staff and insisting on staying with their child rather than delegating some of this care to their husbands. There was a history of similar cyanotic episodes and a head injury in a sibling in case 1 and a burn to a sibling in case 2 . There was reported child abuse to the mothers during their teenage years, in both cases from their fathers. Both mothers also felt that they were unwanted and unloved by their parents and that they did not fit into their families. As in all previously described instances, the mother rather than the father was responsible for the abuse. The first child had been investigated in several specialist hospitals and been subjected to many unpleasant investigations, including a general anaesthetic. He had also received unnecessary drug treatment.

Meadow, who described 32 children with fictitious epilepsy, found that in the 33 siblings of these patients there were seven cot deaths. ${ }^{1}$ One of the 32 children suffered severe cerebral damage. In an earlier report Meadow had described one child with Munchausen syndrome by proxy who died after ingesting large quantities of salt administered by his mother, who was a trained nurse.$^{12}$ In his most recent report Meadow examined the outcome of a larger series, confirming the risk of death and permanent neurological deficits. ${ }^{7}$ There can be little doubt that the children in our report were at high risk of sudden death or neurological damage. The severity of induced hypoxaemia was shown by the loss of consciousness and the electroencephalographic changes. Had death occurred before diagnosis it is unlikely that necropsy would have provided any evidence to distinguish the death from those labelled as cot deaths. Hence it is essential to be aware that smothering may be the cause of cot death. Nevertheless, it is also important to note that case 1 represented only one of 51 children with frequent cyanotic episodes of similar severity and that the remaining 50 cases were due to natural causes.

Most diagnoses of smothering have come from maternal confessions, ${ }^{145} 71314$ sometimes after the child has died. In some cases a nurse has seen the mother suffocating the child. ${ }^{2}$ In only one other report has unequivocal evidence been obtained by using a hidden video camera. ${ }^{3}$ We believe that this technique is essential when there is suggestive but circumstantial evidence. Maternal confessions are often given after a child has died and the cause remains unknown, a setting associated with feelings of guilt. We suspect that Emery is correct in stating that "far more mothers say they have killed their child than did." 15 Nurses observations may place the mother and nurse in direct confrontation in court if the mother denies the smothering (which on the basis of experience is more likely than an admission of guilt in this setting). Video camera surveillance by the police, if handled correctly, provides direct evidence and allows the nursing staff to be distanced from the role of detective. In our cases the police acted professionally and with compassion. We would not hesitate to reapply for their help if suspicious circumstances were present. Furthermore, the simultaneous use of video surveillance and physiological recordings also allowed for the possibility that the mother was not involved in producing the cyanotic episodes, thus avoiding the potential danger of confronting a parent when the suspicion of child abuse is incorrect.

Nevertheless, using covert video surveillance was distressing to all concerned and created an ethical dilemma. We chose to implement video surveillance through police intervention, which inevitably meant that legal action would be taken if the suspicion was confirmed. Superficially this appears to represent a breach of medical confidentiality. We emphasise, however, that a paediatrician's responsibility is primarily to ensure the survival and health of the child. Induced suffocation is a most severe and dangerous form of child abuse with an extremely high risk of brain damage and death. Extracts from the Jasmine Beckford inquiry are highly relevant to our cases: "parental rights cannot be insisted upon by a parent who has abused these rights."16 That is, parents have a duty to look after the best interests of their child, and it is this unique opportunity that confers parental rights over a child. When parents act against their child's best interests they forfeit these rights. Once an unacceptable risk of harm to the child has been proved the child's interests must clearly dictate the paediatrician's actions.

At present there is no legal precedent for polygraphic tape recordings to be accepted as evidence of induced suffocation, and we considered that in the children's interest unequivocal video evidence was required. The lessons learnt from the Jasmine Beckford inquiry are most important: "the immediate treatment and care of an abused child is essential. The need for accurate factual information is paramount in all cases, as it is often the absence of concisely documented information which leads to unnecessary difficulties."16

Smothering has been labelled "gentle" battering. ${ }^{14}$ We reject this. The video and physiological recordings showed that both children struggled violently until they lost consciousness. Considerable force was used to obstruct their airways, and this force was needed for at least 70 seconds before electroencephalographic changes, probably associated with loss of consciousness, occurred. Interestingly, in both cases a soft garment was used to smother the children and no marks were seen on the lips or around the nose.

Examination of the multichannel recordings of physiological variables showed several features, a combination of which may in future prove to be pathognomonic of this type of apnoea, thus avoiding the need for video surveillance. Figures 1 and 2 show the key changes. During a relatively regular breathing pattern suggestive of sleep there was the sudden onset of large body movements with resultant artefacts on both respiratory movement and pulse oximetry traces. These reflect struggling induced by airway obstruction. This degree of movement artefact is not usually seen during the apnoea associated with complex partial seizures. ${ }^{9}$ Body movements occur during prolonged expiratory apnoea (cyanotic breath holding), as these particular cyanotic episodes are often, but by no means always, induced by an attempt to cry or a bout of 
crying. ${ }^{8}$ Nevertheless, they are rarely so large and certainly never as prolonged as those seen in smothering. They do not occur during sleep. Secondly, at about one minute after the onset of the episode there was a series of large breaths occurring at a relatively slow rate with a characteristically prolonged expiratory phase. This "gasping" respiratory pattern is a typical response to severe arterial hypoxaemia. ${ }^{10}$ Thirdly, the episode was associated with a severe degree of sinus tachycardia.

Finally, some 60 seconds after the onset of the episode, there were the large slow waves and a subsequent isoelectric baseline on the electroencephalogram typical of cerebral hypoxaemia. It is important to compare the comparatively long time taken for electroencephalographic changes to occur after smothering with the comparatively short latency in prolonged expiratory apnoea, in which severe hypoxaemia is extremely rapid in onset. ${ }^{8}$ Thus unconsciousness and electroencephalographic changes from cerebral hypoxaemia are present after only 30 seconds in this latter condition, whereas in smothering around 60-70 seconds of complete airway obstruction was present before the associated changes were detected. This adds weight to the hypothesis that prolonged expiratory apnoea is associated with severe ventilatoryperfusion mismatch, probably resulting from widespread alveolar atelectasis. ${ }^{1718}$

It was clearly crucial that both mothers should receive psychiatric treatment. It is difficult to know how much to believe of the histories given concerning their childhood, as so much deception was woven into their stories. Nevertheless, it may be relevant that both mothers reported severe physical abuse from their fathers during adolescence. ${ }^{1920}$ If this can be validated it may have important implications with regard to prevention, diagnosis, and treatment.

In conclusion smothering is a comparatively rare but dangerous and preventable cause of hypoxaemic episodes in infants and young children. Diagnosis by video camera surveillance produces unequivocal evidence, avoids the need for nursing and medical staff to enter into confrontation with the mother in court, and prevents the trauma of confronting the mother with an incorrect suspicion. Unequivocal evidence is crucial to the adequate protection of the child. Future studies may show that a specific pattern on multi- channel recordings of physiological variables is pathognomonic of imposed apnoea, thus avoiding the need for video surveillance.

We thank Dr J Bridson and Dr A Williams for referring the patients and for their help in diagnosing this condition and caring for the families concerned. DPS is supported by Nellcor and the National SIDS Foundation and VAS by the Nuffield Foundation. We are particularly grateful to members of the Chelsea division of the Metropolitan Police for their compassion and professionalism in dealing with these difficult problems.

\section{References}

1 Meadow R. Fictitious epilepsy. Lancet 1984;ii:25-8.

2 Berger D. Child abuse simulating "near miss" sudden infant death syndrome. $\mathcal{I}$ Pediatr 1979;95:554-6.

3 Rosen CL, Frost JD Jr, Bricker T, Tarnow JD, Gillette PC, Dunlavy S. Two siblings with recurrent cardiorespiratory arrest: Munchausen syndrome by proxy or child abuse? Pediatrics 1983;71:715-20.

4 Minford AM. Child abuse presenting as apparent "near-miss" sudden infant death syndrome. BrMed f 1981;282:521.

5 Geelhoed GC, Pemberton PJ. SIDS, seizures, or 'sophaegeal reflux? Another manifestation of Munchausen syndrome by proxy. Med F Aust 1985;143:357-8.

6 McKinlay I. Munchausen's syndrome by proxy. BrMed $\mathcal{F}$ 1986;293:1308.

7 Meadow R. Management of Munchausen syndrome by proxy. Arch Dis Child 1985;60:385-93.

8 Southall DP, Talbert DG, Johnson P, et al. Prolonged expiratory apnoea-a disorder resulting in episodes of severe arterial hypoxaemia in infants and young children. Lancet 1985;ii:571-7.

9 Southall DP, Stebbens V, Abraham N, Abraham L. Prolonged apnoea with severe arterial hypoxaemia resulting from complex partial seizures. Dev Med Child Neurol (in press).

10 Dawes G. Fetal and neonatal physiology. Chicago: Yearbook Medical Publications, 1968:141-59.

11 Lugaresi E, Cirignotta F, Rossi G, Santucci M, Montagna P. Infantile behavioural regression and respiratory impairment. Neuropediatrics 1984;15:211-4.

12 Meadow R. Munchausen syndrome by proxy. The hinterland of child abuse. Lancet 1977;ii:343-5.

13 Emery JL. Child abuse and "near-miss cot death." Br Med f 1981;282:821.

14 Taylor EM, Emery JL. Two-year study of the causes of postperinatal deaths classified in terms of preventability. Arch Dis Child 1982;57:668-73.

15 Emery JL. Infanticide, filicide, and cot death. Arch Dis Child 1985;60:505-7.

16 Beal J, Blom-Cooper L, Brown B, Marshall P, Mason M. A child in trust. The report of the panel of inquiry into the circumstances surrounding the death of Jasmine Beckford. London Borough of Brent: Kingswood Press, 1985.

17 Southall DP, Talbert DG, Johnson P, et al. Prolonged expiratory apnoea and hypoxaemia. Lancet 1985;ii:1125-6.

18 Talbert DG, Southall DP. A bimodal form of alveolar behaviour induced by a defect in lung surfactant-a possible mechanism for sudden infant death syndrome. Lancet 1985;ii:727-8.

19 Korbin JE. Childhood histories of women imprisoned for fatal child maltreatment. Child Abuse and Neglect 1986;10:331-8.

20 Tuteur W, Glotzer M. Further observations on murdering mothers. F Forensic Sci 1966;11: 373-83.

(Accepted 13 March 1987)

\title{
Third trimester placental grading by ultrasonography as a test of fetal wellbeing
}

\author{
JEAN PROUD, ADRIAN M GRANT
}

\begin{abstract}
In a study of $\mathbf{2 0 0 0}$ unselected pregnant women the development of a mature placental appearance (grade 3 ) on ultrasonography by 34-36 weeks' gestation, observed in $15 \%$ of cases, was associated with maternal smoking, low parity, low maternal age, and being white. These women had an increased risk of problems during labour and their babies had an increased risk of low birth weight, poor condition at birth, and perinatal death. The women were
\end{abstract}

Peterborough Maternity Unit, Peterborough PE3 6BP

JEAN PROUD, SCM, MTD, sister in charge of scanning department

National Perinatal Epidemiology Unit, Radcliffe Infirmary, Oxford OX2 6HE ADRIAN M GRANT, DM, MRCOG, epidemiologist

Correspondence to: Dr Grant. randomly allocated to two groups: in one group the result of the placental grading was reported to the clinician responsible for care; in the second the result was noted but not reported. There was a significant decrease in the risk of perinatal death in the group where the grading was known. This reduction was responsible for a difference in the principal outcome index, a heterogeneous group of measures of mortality and morbidity, but this difference was not significant.

This study alone does not justify routine late scanning, and further, larger trials are required. Nevertheless, the results do provide a basis for the reporting of placental grading when ultrasound examination is performed during the third trimester.

\section{Introduction}

The appearance of the placenta on ultrasound examination changes progressively with advancing gestational age, but the speed of these changes varies from pregnancy to pregnancy. Grannum et al first 